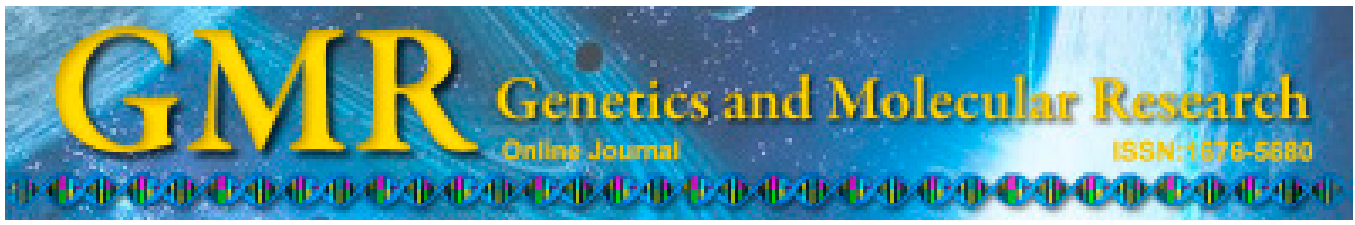

\title{
Pterygium in patients from Goiânia, Goiás, Brazil
}

\author{
G.M. dos Reis ${ }^{1}$, A. de P.R. Júnior ${ }^{1}$, K.S.F. e Silva ${ }^{2}$, D.A. Rodrigues ${ }^{1}$, \\ M.C.S. Gomes ${ }^{1}$, J.V.M. Martins ${ }^{1}$, I.R. da Costa ${ }^{1}$, G.A. Freitas ${ }^{1}$ and \\ K.K.O. Moura ${ }^{2}$ \\ ${ }^{1}$ Replicon, Pontifícia Universidade Católica de Goiás, Goiânia, GO, Brasil \\ ${ }^{2}$ Laboratório de Genética e Biologia Molecular, \\ Universidade Federal de Goiás, Goiânia, GO, Brasil \\ Corresponding author: K.S.F. e Silva \\ E-mail: smallbinho@hotmail.com
}

Genet. Mol. Res. 14 (2): 6182-6188 (2015)

Received August 12, 2014

Accepted February 5, 2015

Published June 9, 2015

DOI http://dx.doi.org/10.4238/2015.June.9.4

\begin{abstract}
Pterygium is an inflammatory and degenerative ocular surface disease in which the conjunctiva on the cornea grows to form a fibrous tissue in the shape of a triangle. The disorder may be characterized by cell proliferation, inflammatory processes, fibrosis, angiogenesis, and destruction of the extracellular matrix. The anomaly is considered a degenerative eye disease and is erroneously confused with cataract. It displays similar features to those of tumors, such as local invasion, metaplasia of epithelial cells, presence of oncogenic viruses (human papilloma virus), inactivation of tumor suppressor genes (e.g., p53), and loss of heterozygosity. The treatment of pterygium is based on factors such as the evolution and progression of the disease, risk factors, symptoms, and patient age. Considerations about the best technique for the surgical removal of pterygium remain controversial, and complications and recurrence are very common. The development of new surgical techniques and adjuvant drugs is thus necessary. This study aims to analyze and compare the frequency of the GSTT1 genotypes in relation to pterygium through statistical analyzes
\end{abstract}


in order to build a genotypic profile for the Replicon patients. The genotypic profile of the GSTT1-null polymorphism in Goiânia showed no significant difference when the frequency of the null genotype was compared between the control and experimental groups. The null genotype was more frequent in the population studied. Furthermore, the GSTT1 genotype was not related to the analyzed risk factors for pterygium, namely gender, ethnicity, family history, occupational exposure, smoking, hypertension, and diabetes.

Key words: GSTT1; Pterygium; Polymorphism; Neoplasia

\section{INTRODUCTION}

Pterygium is an inflammatory and degenerative ocular disease in which the conjunctiva on the cornea grows to form a fibrous tissue in the shape of a triangle (Bradley et al., 2010). Vision may be severely affected in patients with central optical zone involvement. Ultraviolet (UV) exposure is related to the onset and progression of pterygium, although genetic factors can also be involved. The disorder may be characterized by cell proliferation, inflammatory processes, fibrosis, angiogenesis, and degradation of the extracellular matrix (Bradley et al., 2010).

Pterygium is commonly known as "Surfer's Eye" and is erroneously confused with cataract. The affected cells show features similar to those of tumor cells, such as local invasion, metaplasia of epithelial cells, presence of oncogenic viruses (human papilloma virus), inactivation of tumor suppressor genes (p53), and loss of heterozygosity. These features suggest a possible neoplastic nature of the condition (Kau et al., 2006). The treatment of pterygium is based on factors such as progression, risk factors, symptoms, and patient age. The best technique for surgical removal of the pterygium remains controversial, and complications and recurrences are common. The development of new surgical techniques and adjuvant drugs is thus required (Tsai et al., 2005).

Many studies have pointed out the association of pterygium with genetic disorders; however, there is a lack of consensus regarding this issue. Some patients exhibited loss of heterozygosity and microsatellite instability, p53 mutations, Kirsten sarcoma viral mutations, and hypermethylation of the p16 gene promoter (Lekawa-Ilczuk et al., 2011).

Genetic disorders can be investigated using molecular markers. Diagnostic testing based on molecular markers is being increasingly used because the procedure is noninvasive. The p53 gene is an example of a molecular marker and is often investigated if the patient exhibits p53 polymorphisms that could be related to a specific disease (Lekawa-Ilczuk et al., 2011). Some changes are similar to those occurring in neoplastic cells (increased cell proliferation, invasion, and in situ expression of markers associated with a transforming phenotype). Moreover, acute proliferation of the fibrovascular layer is observed in patients with pterygium (Tan et al., 2000).

Additional factors are related to the development of the disease. Free radicals are a group of unstable molecules that include reactive oxygen species (superoxide radicals, hydroxyl, and hydrogen peroxide) and reactive nitrogen species (nitric oxide). Free radicals can react chemically with DNA, lipids, and proteins in a manner that causes DNA damage and lipid peroxidation and may alter the conformation of proteins (Kwon et al., 2005). Oxidative stress occurs when cellular defense mechanisms against free radicals are inefficient, and it is closely related to many disorders that can lead to chronic inflammation, including pterygi- 
um. It is also related to cardiovascular and metaplastic diseases and aging. Moreover, several eye conditions develop because of oxidative stress, including cataract, macular degeneration, glaucoma, keratoconus, and pterygium (Tatlipinar and Akpek, 2005).

UV radiation induces oxidative stress through the activation of endogenous compounds that are sensitive to light. These endogenous substances interact with oxygen to produce reactive species. UV-induced oxidative stress contributes to photoaging because of degradation of the extracellular matrix and damage to the synthesis of collagen and elastin (Ribatti et al., 2007). UV affects ocular structures and stimulates the onset and progression of pterygium. A decrease in the amount of antioxidants in the cornea can be observed with advancing age, which may promote oxidative stress. The lack of antioxidants is even more acute in the event of chronic exposure to UV radiation (Hercules et al., 2006).

One of the earliest cellular responses to UV exposure is the activation of signaling cascades and growth factor receptors through the formation of reactive oxygen species. This response is common on the ocular surface of patients with pterygium, and it is also common in the skin tissue, where UV rays induce the phosphorylation and internalization of epidermal growth factor receptor. The response occurs within minutes after exposure and is followed by the activation of three protein kinases: extracellular signal-regulated kinase, c-Jun N-terminal kinase, and p38 (Di Girolamo, 2005).

Several genes and proteins are related to the metabolism and detoxification of xenobiotics. They are commonly used in studies related to the development of many diseases, including cancer, with an etiology influenced by environmental exposure. Genes encoding enzymes for the activation (phase I reaction) or detoxification (phase II reaction) of xenobiotics are potential targets for studies on genetic susceptibility. Cellular detoxification by enzymes is essential for cellular protection against free radicals. Inactivation of endogenous and xenobiotic toxins allows the preservation of cell integrity in addition to the inhibition of cytotoxic events that may be caused by these compounds and lead to subsequent disease (Young et al., 2010).

Glutathione S-transferase belongs to a family of enzymes that catalyze the nucleophilic attack of reduced glutathione (GST) on compounds with a carbon, a hydrogen, or a sulfur electrophilic atom. There are three families of GST in mammals: cytosolic, mitochondrial, and microsomal (Bolth and Their, 2006). The subfamily GST-Theta comprises two genes known as GSTT1 and GSTT2. They are located at 22q11.2 and are separated by approximately $50 \mathrm{~kb}$. GSTT1 and GSTT2 have 5 and 55\% amino acid identity (Young et al., 2010). The GSTT1-null polymorphism results in the absence of active proteins, and we believe that this polymorphism is related to pterygium. In this study, we examined the GSTT1 polymorphism in patients with pterygium from Goiânia to determine the correlation of this polymorphism with the onset and progression of pterygium.

\section{MATERIAL AND METHODS}

We collected peripheral blood samples $(10 \mathrm{~mL})$ from 90 patients diagnosed with pterygium and 23 healthy individuals to perform molecular analyses of GSTT1. Blood samples were collected at the Hospital Banco de Olhos in the city of Goiânia, Goiás. Molecular analyses were performed at Replicon, PUC, Goiás. All subjects answered a questionnaire pertaining to name, ethnicity, and smoking and/or drinking habits and provided written informed consent.

DNA was extracted from all subjects and purified using the Illustra ${ }^{\mathrm{TM}}$ blood genomic Prep Mini Spin Kit (GE Healthcare ${ }^{\circledR}$, USA). Subsequently, the samples were quantified using 
NanoVue ${ }^{\mathrm{TM}}$ Plus (GE Healthcare ${ }^{\circledR}$ ) according to manufacturer instructions. We used DNA samples with a minimum concentration of $5 \mathrm{ng} / \mu \mathrm{L}$ for analysis.

After extraction, the DNA samples were subjected to amplification by polymerase chain reaction (PCR) to detect allele-specific polymorphisms in GSTT1. The PCR products were subjected to electrophoresis on $2 \%$ agarose gel with an electric field of $10 \mathrm{~V} / \mathrm{cm}$ and stained with ethidium bromide $(5 \mathrm{mg} / \mathrm{mL})$. The gel was visualized and documented by UV transillumination on the ImageMaster ${ }^{\mathrm{TM}} \operatorname{VDS}^{\circledR}$ (Amersham Pharmacia Biotech, USA). Subjects with one or two copies of the GSTT1 allele are considered to have a normal genotype, while those without any copies of the allele are considered to have a null genotype. Genotypes were recorded in spreadsheets using the Excel ${ }^{\circledR}$ Microsoft Corp 2003 software. Subsequently, the chi-square test or the Fisher exact test was performed to investigate possible associations between the results of the molecular analyses and pterygium. The BioEstat ${ }^{\mathbb{B}} 3.0$ software (Mamirauá/MCT-CNPq Civil Society) was used for all analyses.

\section{RESULTS}

We analyzed the frequencies of the GSTT1 genotypes in the case and control groups (Table 1). In the case group $(\mathrm{N}=91), 17.6 \%(16 / 91)$ subjects exhibited the GSTT1-present genotype and $82.4 \%$ (75/91) patients exhibited the GSTT1-null genotype. In the control group $(\mathrm{N}=23), 4.3 \%(1 / 23)$ subjects exhibited the GSTT1-present genotype and 95.7\% (22/23) subjects exhibited the GSTT1-null genotype. There were no significant differences in the frequencies of the GSTT1-present and -null genotypes between case and control groups $(\mathrm{P}=0.096)$.

\begin{tabular}{|c|c|c|c|c|c|}
\hline & \multicolumn{2}{|c|}{ GSTT1 present } & \multicolumn{2}{|c|}{ GSTT1 null } & \multirow[t]{2}{*}{$\mathrm{P}$} \\
\hline & $\mathrm{N}$ & $\%$ & $\mathrm{~N}$ & $\%$ & \\
\hline Case $(\mathrm{N}=91)$ & 16 & 17.6 & 75 & 82.4 & 0.0960 \\
\hline Control $(\mathrm{N}=23)$ & 1 & 4.3 & 22 & 95.7 & \\
\hline
\end{tabular}

Fisher exact test.

Table 2 shows comparisons between the case and control group females and between the case and control group males in terms of the GSTT1 genotype. GSTT1 polymorphism analysis showed that $20 \%(10 / 50)$ female subjects in the case group expressed GSTT1 while $80 \%(40 / 50)$ did not. In the control group, 8.3\% (1/12) female subjects exhibited the GSTT1present genotype, while $91.7 \%$ (11/12) showed the GSTT1-null genotype; the results were not statistically significant $(\mathrm{P}=0.316)$.

Table 2. Difference between male and female patients with regard to the GSTT1-present and -null genotypes.

\begin{tabular}{|c|c|c|c|c|c|c|c|}
\hline \multirow[t]{2}{*}{ Gender } & \multicolumn{2}{|c|}{ Present } & \multicolumn{2}{|c|}{ Null } & \multicolumn{2}{|c|}{ Total } & \multirow[t]{2}{*}{$\mathrm{P}$} \\
\hline & $\mathrm{N}$ & $\%$ & $\mathrm{~N}$ & $\%$ & $\mathrm{~N}$ & $\%$ & \\
\hline \multicolumn{8}{|l|}{ Female } \\
\hline Case & 10 & 20.0 & 40 & 80.0 & 50 & 100.0 & \multirow[t]{2}{*}{0.3160} \\
\hline Control & 1 & 8.3 & 11 & 91.7 & 12 & 100.0 & \\
\hline \multicolumn{8}{|l|}{ Male } \\
\hline Case & 6 & 14.6 & 35 & 85.4 & 41 & 100.0 & \multirow[t]{2}{*}{0.2209} \\
\hline Control & 0 & 0.0 & 11 & 100.0 & 11 & 100.0 & \\
\hline
\end{tabular}

Fisher exact test. 
With regard to the male subjects, $14.6 \%$ (6/41) expressed GSTT1, whereas $85.4 \%$ (35/41) exhibited the polymorphic genotype in the case group. In the control group, no male subject exhibited the GSTT1-present genotype, while 100\% (11/11) showed the GSTT1-null genotype; the differences were not statistically significant $(\mathrm{P}=0.2209)$.

Table 3 shows the genotype distribution among white, black, and brown patients in the case and control groups. In the case group, 24\% (12/50) and 76\% (38/50) white patients exhibited the GSTT1-present and -null genotypes, respectively, while $8.3 \%(2 / 24)$ and $91.7 \%$ (22/24) brown patients showed the GSTT1-present and -null genotypes, respectively, and $11.8 \%(2 / 17)$ and $88.2 \%(15 / 17)$ black patients showed the GSTT1-present and -null genotypes, respectively.

Table 3. Comparison of skin color according to the GSTT1 polymorphism genotype in case and control groups.

\begin{tabular}{|c|c|c|c|c|c|c|c|}
\hline \multirow[t]{3}{*}{ Groups } & \multicolumn{6}{|c|}{ Skin color* } & \multirow[t]{3}{*}{$\mathrm{P}$} \\
\hline & \multicolumn{2}{|c|}{ White } & \multicolumn{2}{|c|}{ Brown } & \multicolumn{2}{|c|}{ Black } & \\
\hline & $\mathrm{N}$ & $\%$ & $\mathrm{~N}$ & $\%$ & $\mathrm{~N}$ & $\%$ & \\
\hline \multicolumn{8}{|l|}{ Case } \\
\hline Present & 12 & 24.0 & 2 & 8.3 & 2 & 11.8 & \\
\hline Null & 38 & 76.0 & 22 & 91.7 & 15 & 88.2 & 0.1791 \\
\hline Total & 50 & 100.0 & 24 & 100.0 & 17 & 100.0 & \\
\hline \multicolumn{8}{|l|}{ Control } \\
\hline Present & 1 & 6.2 & 0 & 0.0 & 0 & 0.0 & \\
\hline Null & 15 & 93.8 & 3 & 100.0 & 4 & 100.0 & 0.6888 \\
\hline Total & 16 & 100.0 & 3 & 100.0 & 4 & 100.0 & \\
\hline
\end{tabular}

G test. *Reported by patient.

In the control group, $6.2 \%(1 / 16)$ and $93.8 \%(15 / 16)$ white patients exhibited the GSTT1-present and -null genotypes, respectively, while 100\% (3/3) brown and black (4/4) patients showed the GSTT1-null genotype. The results for the GSTT1-null genotype with regard to skin color were not statistically significant $(\mathrm{P}=0.179$; Table 3$)$.

We also analyzed the possible correlations between the presence of the GSTT1-null polymorphism and risk factors for pterygium, including a family history of eye problems, occupational exposure, smoking, drinking, systemic hypertension, and diabetes; none of the relations were statistically significant.

\section{DISCUSSION}

Several cases of pterygium are related to complex genetic disorders caused by a combination of different risk factors. However, genetic or environmental factors do not act alone in disease development; the same factors can be observed in subjects without pterygium (Fan et al., 2010).

Global studies have investigated whether genetic polymorphisms in antioxidant enzymes (GSTs) contribute to the onset of diseases such as pterygium. A group of researchers from Iran (Othman et al., 2012) examined 112 patients, and the results support the idea that the protein encoded by GSTT1 has a protective effect against oxidative stress caused by degenerative eye diseases such as macular degeneration and pterygium. The results showed no statistically significant differences in the frequency of the GSTT1-null and -present genotypes between the control and case groups (Othman et al., 2012), thus supporting the results of the present study. 
A group of scientists from Saudi Arabia (Abu-Amero et al., 2009) examined null polymorphisms in GSTs, including GSTT1, in patients with optic neuropathies and found that the prevalence of the null genotype was significantly higher in the neuropathy group than in the control group. This result is not consistent with the findings of the present study, where no statistically significant differences were observed. The discrepancy between these results can be explained by differences in the sample size; our study included 91 patients while the previous study (Abu-Amero et al., 2009) included 228 patients.

There was no significant difference in the prevalence of pterygium between male and female subjects with the null genotype in the present study. A group of researchers from India (Bhardwaj et al., 2013) examined rural workers and found no significant differences between the number of male and female subjects with pterygium, consistent with the findings of our study. In contrast, a survey conducted in Singapore (Wong et al., 2001) showed statistically significant differences in the prevalence of the disease between male and female subjects, with the prevalence being higher in males.

Our results showed no significance differences in the prevalence of pterygium and the GSTT1-null polymorphism among different ethnic groups $(\mathrm{P}=0.1791)$. The scientific literature indicates a higher prevalence of pterygium in the Asian population, particularly Malaysians (Ang et al., 2012). A study group from Barbados (Luthra et al., 2001) showed that ethnicity influences the development of pterygium; in a sample of 4709 patients, they showed that pterygium was more frequent in the population of that country. There was no significant correlation between occupational exposure and the onset of pterygium. The scientific literature indicates that occupational exposure is a risk factor for the development of the disease (Hercules et al., 2006). A study from Taiwan demonstrated different results. They found a significant correlation between the onset of pterygium and occupational exposure $(\mathrm{P}<0.05)$ and concluded that an hour of exposure to sunlight every day for a year increases the chances of developing pterygium in $0.8 \%$ patients (Tang et al., 1999).

Furthermore, studies conducted in Iran showed that smoking was not associated with the onset of pyterigium in an analysis of 6497 residents of Tehran (Fotouhi et al., 2010).

A group of scientists from Spain analyzed the relationship between the onset of pterygium and alcohol consumption (Viso et al., 2011) and found no correlation, which is in accordance with our results. In contrast, a study conducted in India (Marmamula et al., 2013) found a significant correlation between alcohol consumption and the onset of pterygium in a sample of 5586 patients.

In our study, diabetes and hypertension were not correlated with the onset of pyterigium, and a study conducted in China confirms our results in a sample of 2742 patients (Zhong et al., 2012).

In conclusion, genotypic profiling of the GSTT1-null polymorphism in Goiânia showed no statistically significant difference in the prevalence of the null genotype between the case and control groups. Moreover, the GSTT1-null genotype was not related to the risk factors analyzed: gender, ethnicity, family history, occupational exposure, smoking, hypertension, and diabetes.

\section{ACKNOWLEDGMENTS}

Research supported by Pontifícia Universidade Católica de Goiás, Goiânia, Brazil (UCG/Prope/MGene). We are grateful to the Replicon staff and students who made this research possible. 


\section{REFERENCES}

Abu-Amero KK, Milcarek B and Bosley TM (2009). GSTM1 and GSTT1 deletion genotypes in various spontaneous optic neuropathies in Arabs. Br. J. Ophthalmol. 93: 1101-1104.

Ang M, Li X, Wong W, Zheng Y, et al. (2012). Prevalence of and racial differences in pterygium: a multiethnic population study in Asians. Ophthalmology 119: 1509-1515.

Bhardwaj VMS, Das AP and Bhardwaj G (2013). Pterygium - a study which was done on a rural based population. J. Clin. Diagn. Res. 7: 1936-1937.

Bolth H and Their R (2006). Relevance of the deletion polymorphisms of the glutathione S-tranferases GSTT1 and GSTM1 in pharmacology and toxicology. Curr. Drug Metab. 7: 613-628.

Bradley JC, Yang W, Bradley RH, Reid TW, et al. (2010). The science of pterygia. Br. J. Ophthalmol. 94: 815-820.

Di Girolamo N, Coroneo M and Wakefield D (2005). Epidermal growth factor receptor signaling is partially responsible for the increased matrix metalloproteinase-1 expression in ocular epithelial cells after UVB radiation. Am. J. Pathol. 167: 489-503.

Fan BJ, Liu K, Wang DY, Tham CC, et al. (2010). Association of polymorphisms of tumor necrosis factor and tumor protein p53 with primary open-angle glaucoma. Invest. Ophthalmol. Vis. Sci. 51: 4110-4116.

Fotouhi A, Hashemi H, Khabazkhoob M and Mohammad K (2009). Prevalence and risk factors of pterygium and pinguecula: the Tehran Eye Study. Eye 23: 1125-1129.

Hercules LA, Viveiros MM, Schellini SA, Candeias J, et al. (2006). Exposure of Tenon's capsule fibroblasts of pterygium to cyclosporin 0.05\%. Arq. Bras. Oftalmol. 69: 831-835.

Kau HC, Tsai CC, Lee CF, Kao SC, et al. (2006). Increased oxidative DNA damage, 8-hydroxydeoxyguanosine, in human pterygium. Eye 20: 826-831.

Kwon YS, Hong HS, Kim JC, Shin JS, et al. (2005). Inhibitory effect of rapamycin on corneal neovascularization in vitro and in vivo. Invest. Ophthalmol. Vis. Sci. 46: 454-460.

Lekawa-Ilczuk A, Antosz H, Rymgayłło-Jankowska B and Zarnowski T (2011). Expression of double strand DNA breaks repair genes in pterygium. Ophthalmic Genet. 32: 39-47.

Luthra R, Nemesure BB, Wu SY, Xie SH, et al. (2001). Frequency and risk factors for pterygium in the Barbados Eye Study. Arch. Ophthalmol. 119: 1827-1832.

Marmamula S, Khanna RC and Rao GN (2013). Population-based assessment of prevalence and risk factors for pterygium in the South Indian state of Andhra Pradesh: the Andhra Pradesh Eye Disease Study. Invest. Ophthalmol. Vis. Sci. 54: 5359-5366.

Othman H, Gholampour AR, Saadat I, Farvardin-Jahromoi M, et al. (2012). Age-related macular degeneration and genetic polymorphisms of glutathione S transferases M1 (GSTM1) and T1 (GSTT1). Mol. Biol. Rep. 39: 3299-3303.

Ribatti D, Nico B, Maxia C, Longo V, et al. (2007). Neovascularization and mast cells with tryptase activity increase simultaneously in human pterygium. J. Cell Mol. Med. 11: 585-589.

Tan DT, Liu YP and Sun L (2000). Flow cytometry measurements of DNA content in primary and recurrent pterygia. Invest. Ophthalmol. Vis. Sci. 41: 1684-1686.

Tang FC, Chen SC, Lee HS, Lin WF, et al. (1999). Relationship between pterygium/pinguecula and sunlight exposure among postmen in central Taiwan. Zhonghua Yi Xue Za Zhi 62: 496-502.

Tsai YY, Cheng YW, Lee H, Tsai FJ, et al. (2005). P53 gene mutation spectrum and the relationship between gene mutation and protein expression in pterygium. Mol. Vis. 11: 50-55.

Tatlipinar S and Akpek EK (2005). Topical ciclosporin in the treatment of ocular surface disorders. Br. J. Ophthalmol. 89: 1363-1367.

Viso E, Gude E and Rodríguez-Ares MT (2011). Prevalence of pinguecula and pterygium in a general population in Spain. Eye 25: 350-357.

Wong TY, Foster PJ, Johnson GJ, Seah SK, et al. (2001). The prevalence and risk factors for pterygium in an adult Chinese population in Singapore: the Tanjong Pagar survey. Am. J. Ophthalmol. 131: 176-183.

Young CH, Lo YL, Tsai YY, Shih TS, et al. (2010). CYP1A1 gene polymorphisms as a risk factor for pterygium. Mol. Vis. 16: 1054-1058.

Zhong H, Cha X, Wei T, Lin X, et al. (2012). Prevalence of and risk factors for pterygium in rural adult Chinese populations of the Bai nationality in Dali: the Yunnan Minority Eye Study. Invest. Ophthalmol. Vis. Sci. 53: 6617-6621. 